\title{
Using climate information for improved health in Africa: relevance, constraints and opportunities
}

\author{
Stephen J. Connor, Pietro Ceccato, Tufa Dinku, Judy Omumbo, Emily K. Grover-Kopec, \\ Madeleine C. Thomson \\ International Research Institute for Climate and Society (IRI), The Earth Institute at Columbia University, \\ Palisades, New York 10964-8000, USA
}

\begin{abstract}
Good health status is one of the primary aspirations of human social development and, as a consequence, health indicators are key components of the human development indices by which we measure progress toward sustainable development. Certain diseases and ill health are associated with particular environmental and climate conditions. The timeframe of the Millennium Development Goals (MDGs) demands that the risks to health associated with current climate variability are more fully understood and acted upon to improve the focus of resources in climate sensitive disease control, especially in sub-Saharan Africa, where good epidemiological surveillance data are lacking. In the absence of high-quality epidemiological data on malaria distribution in Africa, climate information has long been used to develop malaria risk maps illustrating the climatic suitability boundaries for endemic transmission. However, experience to date has shown that it is difficult in terms of availability, timing and cost to obtain meteorological observations from national meteorological services in Africa. National health services generally find the costs of purchasing these data prohibitive given their competing demands for resources across the spectrum of health service requirements. Some national health services have tried to overcome this access problem by using proxies derived from satellites, which tend to be available freely, in 'near-real-time' and therefore offer much promise for monitoring applications. This paper discusses the issues related to climate and health, reviews the current use of climate information for malaria endemic and epidemic surveillance, and presents examples of operational use of climate information for malaria control in Africa based on Geographical Information Systems and Remote Sensing.
\end{abstract}

Keywords: malaria, early warning system, GIS, remote sensing, climate.

\section{Health and development}

Good health status is one of the primary aspirations of human social development and, as a consequence, health indicators are key components of the human development indices by which we measure progress toward sustainable development. The high profile of health in development is apparent in the near-universally adopted Millennium Development

Corresponding author:

Pietro Ceccato

International Research Institute for Climate and Society (IRI)

The Earth Institute at Columbia University

227 Monell, Lamont Campus, 61 Route 9W, Palisades

New York 10964-8000, USA

Tel. +1 8456804425 Fax +1 8456804865

Email: pceccato@iri.columbia.edu
Goals (MDGs) for 2015 (Sachs, 2004; Sachs and McArthur, 2005), where three of the eight Goals are directly related to health care intervention and outcomes: Goal 4 - reduce by two thirds the mortality rate among children under five; Goal 5 - reduce by three quarters the maternal mortality rate; Goal $6-$ halt and begin to reduce the spread of HIV-AIDS, malaria and other infectious diseases. A number of the other goals are indirectly related to health status (e.g. Goal 1 - eradicate extreme poverty and hunger) as malnutrition is considered the single most important risk factor to health (WHO, 2002), and clearly our health prospects rely heavily on the sustainability of our environment and essential ecosystems (i.e. Goal 7; WHO-WMO-UNEP, 2003).

Societies have tended to experience different types of health problems at different stages of socio-eco- 
nomic development. Clearly one would expect health problems facing rural African communities to differ from those facing urban populations in Western Europe, for example. One perhaps overly simple aid to understanding these differences is the 'epidemiological transition' which links changing disease patterns over time with changes in the prevailing phase of social, economic, demographic and ecological conditions. For example, first phase subsistence agriculture, high fertility, high infant death rate, low life expectancy, famine and infectious disease are the main causes of death; second phase - gradual improvements in agriculture, nutrition and sanitation reduce crude death rate; third phase - intensive agriculture/industrialization, lower fertility, longer life expectancy, non-communicable degenerative disease becomes the main cause of death (Omran, 1971). Beyond such generalization we must not lose sight of the fact that health problems are not homogenous in any country, at any time, regardless of their stage of development, and disparities occur between social class, gender and religion, although the poorest portion of the population is generally at greatest risk (Phillips and Verhasselt, 1994; Smith and Ezzati, 2005).

In sub-Saharan Africa where the vast majority of the population is yet to complete this transition, the greatest burden of disease morbidity and related mortality stems primarily from infectious disease. HIV-AIDS, tuberculosis (TB), and malaria are widely recognized as the three major culprits. Co-infection of these diseases is known to exacerbate each other making care of sufferers particularly challenging to health services and communities operating with poor resources in sub-Saharan Africa (WHO, 2002; WHO, 2005a). These three preventable diseases have come to be seen as a significant constraint to Africa's development prospects. Calls have been made for massive investment in health services and control programs in the most affected countries (WHO, 2001). Since its establishment in 2002 the Global Fund for AIDS, TB and Malaria has mobilized significant financial (US\$4.4 billion to date), technical and political resources towards the fight against these three diseases, especially in Africa (Global Fund Grant Commitments \& Disbursements http://www.theglobalfund.org/en/funds_raised/commitments/).

With Global Fund grant commitments and disbursements now underway, attention is beginning to focus on a large group of diseases confined to the "other" category by health policy makers and politicians. These so-called neglected diseases are the viral, bacterial, and parasitic infections, together with acute respiratory infections and diarrhoeal diseases, which are all too common in the poorer countries of the world. Despite the availability of cost-effective, successful control interventions, large numbers of the world's poorest people remain afflicted or at risk from this group of 'other' diseases. Children are most at risk of dying from infectious disease and current estimates suggest that somewhere between 10 and 15 million children die per year from the combined effects of infectious disease and malnutrition (Jones et al., 2003; WHO, 2004a). Sub-Saharan Africa is the only region in the world which is not currently making progress in reducing child mortality. The disparity between these estimates highlights the fact that we do not have sufficiently reliable surveillance data on disease incidence in many resource poor countries. Good surveillance data are essential for resource allocation and planning for effective disease control and health care services. Strengthening of national health systems in developing countries is now seen as a priority in helping health services decide which diseases are priorities, and to help target resources according to who, where and when populations are affected.

\section{Health and climate}

Certain diseases and ill health are associated with particular environmental conditions, season, and climate (Haines and Patz, 2004). This was recognized by the ancient writers of Vedic literature, by Hippocrates, and is the focus of considerable research today. Climate may affect health through a number of direct mechanisms (e.g. heat stress) or, more com- 
monly, through indirect processes including:

(i) water source quality (i.e. water-borne disease);

(ii) food security (i.e. nutritional status and consequently immuno-suppression);

(iii) economy (i.e. the capacity of individuals or states to provide protection from harm or the management of disease through the provision of drugs);

(iv) transport and infrastructure (i.e. extreme weather events may limit access to health care);

(v) infectious disease (i.e. the impact of climate on the pathogen, vector, intermediate host and human host).

The timeframe of the MDGs demands that the risks to health associated with current climate variability are more fully understood and acted upon to improve the focus of resources in climate sensitive disease control, especially in sub-Saharan Africa, where good epidemiological surveillance data are lacking. While we know little of the implications of future climate change we can be sure that health will remain a major factor in social well-being. If we are successful in helping vulnerable communities to benefit from significant investments in health services and improved management of climate sensitive disease in the immediate future, then we will at least face the potential impacts of climate change with a lower baseline of infections. We may also have a better knowledge and human resource capacity to manage our rapidly globalizing development in a healthier and more sustainable way.

The focus of this paper is to address the operational use of climate information for infectious disease control in Africa. This is the only aspect of climate and health that has been systematically studied on the continent, and there are active attempts to use climate information in decision making within the public health sector.

\section{Current use of climate information}

\section{Climate sensitive diseases}

Socio-economic, demographic and immunological factors play an important role in determining the vulnerability of individuals and communities to disease. Climate, however, largely determines the spatial and seasonal distribution of many infectious diseases in Africa, due, in part, to their inadequate control. It can also be a key determinant of inter-annual variability of disease incidence, including epidemics, as well as longer term trends. Climate information may, therefore, help service a range of health care planning decisions and may be used to improve our assessment of the impact of interventions for climate-sensitive diseases. Table 1 summarizes how an understanding of these climate relationships to disease outcome can be used by health staff and health policy makers to improve short and long term disease control in both the short and long term.

The World Health Organization has identified a number of 'climate sensitive' diseases ${ }^{1}$, the most prominent of which is malaria, but also includes a number of the so-called neglected diseases (WHO, 2005 b). While recognizing that socio-economic, demographic and immunological factors play an important role in the vulnerability of communities to these diseases, it is apparent that climate variability plays an important role in 'triggering' periodic epidemics. The WHO promotes and supports efforts to establish operational methods of using climate information in 'Early Warning Systems' (EWS) to help health services to manage these diseases more effectively. To date, research and operational advances are most apparent in the development of integrated early warning systems for malaria (WHO, 2004b). Inter-decadal variability in climate is also known to affect the distribution of disease and the vulnerability of populations to disease. For example, the thirty-year Sahelian drought has been associated with changes in the distribution of a

\footnotetext{
1 WHO identified 14 candidate diseases meeting their criteria for potential in using climate information in predicting epidemics, these are: malaria, African trypanosomiasis, leishmaniasis, yellow fever, cholera, meningitis, dengue, Rift Valley Fever, West Nile Virus, Japanese encephalitis, St. Louis encephalitis, Murray Valley encephalitis, Ross River virus and influenza. They acknowledge however, that this list does not include several respiratory and non-communicable diseases which may also be climate sensitive.
} 
Table 1. Aspects of disease influenced by climate and potential for informational tools.

\begin{tabular}{|c|c|c|}
\hline Disease Pattern & Informational tool & Type of climate information \\
\hline Spatial & $\begin{array}{l}\text { Risk maps for endemic and epidemic prone } \\
\text { regions }\end{array}$ & $\begin{array}{l}\text { Requires appropriate climatology based on historical data of } \\
\text { relevant climate variables - with uncertainties known }\end{array}$ \\
\hline Seasonal & $\begin{array}{l}\text { Seasonal calendars for improving the timing } \\
\text { of interventions and reducing mis-diagnosis } \\
\text { of clinical disease }\end{array}$ & $\begin{array}{l}\text { Requires appropriate climatology based on historical data of } \\
\text { relevant climate variables at appropriate spatial scales and } \\
\text { with uncertainties known }\end{array}$ \\
\hline $\begin{array}{l}\text { Inter-annual } \\
\text { variability }\end{array}$ & $\begin{array}{l}\text { Informed district policies for epidemic - } \\
\text { endemic disease }\end{array}$ & $\begin{array}{l}\text { Requires standard climatology relevant to monitoring decadal } \\
\text { shifts in the recent distribution of climate sensitive disease } \\
\text { outcomes }\end{array}$ \\
\hline $\begin{array}{l}\text { Inter-annual } \\
\text { variability }\end{array}$ & $\begin{array}{l}\text { Informed district policies for epidemic - } \\
\text { endemic disease }\end{array}$ & $\begin{array}{l}\text { Requires standard climatology relevant to monitoring decadal } \\
\text { shifts in the recent distribution of climate sensitive disease } \\
\text { outcomes }\end{array}$ \\
\hline Trend & $\begin{array}{l}\text { Understanding of historical trends in disease } \\
\text { data and the potential impact of long-term } \\
\text { climate change }\end{array}$ & Long time series of appropriate climate data \\
\hline $\begin{array}{l}\text { Assessment of } \\
\text { impact of } \\
\text { interventions }\end{array}$ & $\begin{array}{l}\text { Understanding the relative contribution of } \\
\text { climate to changes in the outcome of a } \\
\text { variable monitored to assess the impact of a } \\
\text { health intervention }\end{array}$ & $\begin{array}{l}\text { Requires time series of climate data, of appropriate spatial } \\
\text { and temporal scale, concurrent with the outcome variables } \\
\text { used in the assessment of the impact of the intervention }\end{array}$ \\
\hline
\end{tabular}

number of major diseases in West Africa (Thomson et al., 2004a,b).

\section{Evidence-based health policy}

The role of evidence in the creation of health policy has been strongly promoted in recent years through, for example, the Cochrane ${ }^{2}$ and Campbell ${ }^{3}$ Systematic Review Systems.

Before using climate information in routine decision making, health policy advisors and decision makers often ask for:

(i) evidence of the impact of climate variability on their specific outcome of interest, and

(ii) evidence that using climate information is a cost-effective and practical means to improving health outcomes.

This demand asserts the importance of evidence in effective policy making whilst simultaneously placing climate in a broader context as only one

\footnotetext{
$2_{\text {http://www.cochrane.org/ }}$

3 http://www.campbellcollaboration.org/
}

amongst several imperatives. If evidence is to have a greater impact on policy and practice then four key requirements would seem to be necessary before such an agenda can be developed:

(i) agreement as to the nature of acceptable evidence;

(ii) a strategic approach to the creation of evidence, together with the development of a cumulative knowledge base;

(iii) effective dissemination and access to knowledge;

(iv) initiatives to increase the uptake of evidence in both policy and practice.

Improving routine health surveillance is surely one essential component of this strategic approach but more effective partnerships need to be developed to integrate the climate factor.

\section{Malaria and climate}

Malaria is a major public health problem in Africa. It is endemic throughout most of subSaharan Africa and its control is recognized as critical to achieving the MDGs. Indeed the recently 
published Global Strategic Plan for Roll Back Malaria 2005-2015 has stated: "six out of eight Millennium Development Goals can only be reached with effective malaria control in place" (Global Strategic Partnership for Roll Back Malaria 2005-2015 http://www.rollbackmalaria.org/forumV/ docs/gsp_en.pdf). Malaria will therefore be used here as the primary disease to illustrate how climate information can be used to inform health services in endemic and epidemic prone countries. Endemic and epidemic malaria are sometimes referred to as 'stable' and 'unstable' malaria respectively.

\section{Endemic malaria}

The greatest burden of malaria in Africa is borne by populations in regions where the disease pathogen is perennially present in the community. In these regions, the environment is conducive to interactions between Anopheles mosquitoes, malaria parasites and human hosts because they contain surface water in which mosquitoes can lay their eggs, humid conditions which facilitate adequately long adult mosquito survival and relative warmth which allows both the mosquito and the malaria parasite to develop rapidly. In addition, housing quality is generally poor and offers little protection from human-mosquito interaction. When malaria control measures are inadequate, as is the case in much of sub-Saharan Africa, then the disease distribution is closely linked with seasonal patterns of the climate and local environment. Those most vulnerable to endemic malaria are young children who have yet to acquire immunity to the disease, pregnant women whose immunity is reduced during pregnancy, and non-immune migrants or travelers.

Risk maps and seasonal calendars for endemic malaria control planning

In the absence of high-quality epidemiological data on malaria distribution in Africa, climate information has long been used to develop malaria risk maps illustrating the boundaries of climatic suitabil- ity for endemic transmission. The best known of these are produced by the Pan-African based MARA Collaboration (MARA, 1998; Craig et al., 1999). More recently malaria suitability maps have been produced in an online interactive format to enable graphic temporal information (seasonality) to be queried and displayed along with the spatial information (Grover-Kopec et al., 2006). The Climate Suitability Maps for Malaria Transmission are available at: http://iridl.ldeo.columbia.edu/maproom/.Health/.Regional/.Africa/.Malaria/.CSMT/. Seasonal information allows the development of malaria control calendars. Such products promise to help health services focus control activities such as drug procurement and anti-vector spraying more appropriately. Seasonal calendars may also help avoid misdiagnosis and inappropriate drug treatment, both of which are vital to reducing the development rate of parasite-drug resistance.

\section{Inter-decadal variability and longer-term trends}

We need to be aware, however, of some of the shortfalls in the climate data being used in such products. One climatology data set for Africa used in several mapping products, including those of MARA, is comprised of continental surfaces of temperature and rainfall compiled from interpolated observations collected during the period 1920-1980 (Hutchinson et al., 1995). While a sixty-year data set is valuable for developing a climatology, it does not fully capture the more recent trends, such as the Sahelian drought, known to influence current disease distribution (Thomson et al., 2004a,b). Resulting disease distribution maps may therefore mis-represent the current spatial distribution. In the online products described above the climatology is developed from observations over the period 19512000 (Hulme et al., 2004). This partly takes care of the problem of relating climate to recent disease distributions.

However, the number of observations available from Africa to produce this climatology has been in decline over the past twenty years and this raises 
questions about the employed interpolation methods and the adequacy of the data (e.g. should the interpolation only be applied where there is an adequate number of observing stations?). Integrating temperature into disease risk models poses a particular challenge. This is very important in the highlands of east and southern Africa where temperature limits the extrinsic development rate of malaria and many other parasites. A fierce debate exists in the literature on the contribution of recently increasing temperatures to epidemic malaria in the highlands. The debate is confounded by poor understanding by health researchers on the correct use and interpretation of climate information products and, conversely, limited understanding of disease transmission dynamics within the climate community. Thus, caution needs to be exercised when national and subnational maps are extracted from these types of continental-scale products because the results could be very misleading (Pascual et al., 2006)

There are, however, considerably more observed data, and more recent data, in national meteorological service archives than is available to the globallevel archives from which these climatology products are derived. Collating and incorporating these additional data into national climatology products would be highly beneficial to national development sectors, including health. Ideally, the development of national and sub-national distribution maps for malaria and other climate sensitive diseases should utilize these data ${ }^{4}$. Otherwise national health services are being supplied with sub-optimal information.

\section{Epidemic malaria}

Epidemic malaria tends to occur along the geographical margins of endemic regions, when the conditions supporting the equilibrium between the human, parasite and mosquito vector populations are disturbed. This leads to a sharp but temporary

\footnotetext{
4 This is true also of non-health applications such as farming systems and food security zone maps which rely heavily on interpolated climate information.
}

increase in disease incidence. More than 124 million Africans live in such areas, and experience epidemics causing around 12 million malaria episodes and up to 310,000 deaths annually (Worrall et al., 2004). All age groups are vulnerable to epidemic malaria, because exposure to malaria is infrequent in these regions and, therefore, little acquired immunity to this life threatening disease is developed (Kizewski and Teklehaimanot, 2004).

Epidemics can occur for a variety of reasons. Some epidemics are caused by human activities, such as an irrigation scheme in a warm, semi-arid environment, the displacement of non-immune populations between highland and lowland regions, or a breakdown in pre-existing levels of malaria control. Rarely, they may also follow the accidental introduction of an exotic mosquito species. These human-induced epidemics are less likely to return to the pre-existing equilibrium and may lead to endemic transmission (see Fig. 1).

In the case of 'classic' or 'true' epidemics, the changes in suitability for transmission are brought about by natural causes such as climate anomalies in regions where the environment does not normally allow sufficient mosquito and parasite development to occur. These 'true' epidemics often occur in the desert-fringe or highland-fringe areas, which are typically too dry or cool, respectively, to support transmission. The climate anomalies are often periodic and temporary, and there is often a return to the original unstable state. Examples include the epidemics occurring in the semi-arid areas of Southern Africa in 1996-1997, East Africa in 19971998, and the West African Sahel in 1999-2000, all of which were associated with large-scale unusually heavy rainfall (WHO, 2004b). Being poorly prepared, health services often become rapidly overwhelmed, leading to perhaps ten times more malaria-related deaths than in non-epidemic years, across all age ranges (Kizewski and Teklehaimanot, 2004; Brown et al., 1998). Epidemics also occur occasionally as enhanced seasonal peaks in regions where levels of seasonal transmission are normally low. Fig. 1 illustrates three different types of epidemic sit- 


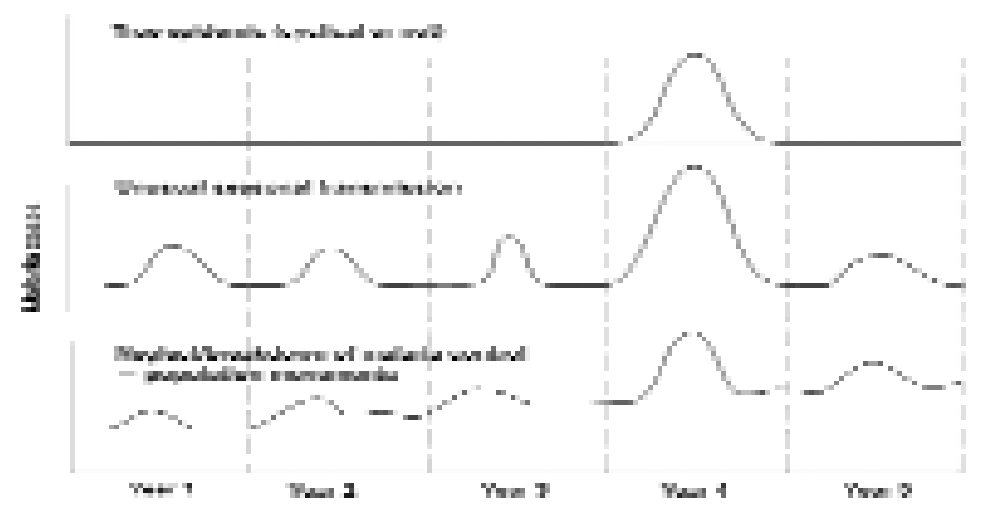

Fig. 1. A conceptual diagram of three different epidemic scenarios.

The first (top) situation represents a 'true' epidemic, i.e. an infrequent event occurring in areas where the disease does not normally occur. This type of epidemic is often associated with warm arid and semi-arid regions and may be cyclical in nature. The second (middle) situation represents an unusually high peak in transmission in areas where malaria is normally present on a seasonal basis. This type of epidemic is often associated with hypoendemic or mesoendemic settings such as the highland fringes and may also be cyclical in nature. The third (bottom) situation represents a "resurgent out-break" where neglect or breakdown in control allows malaria to return to its higher 'pre-control' level of endemicity. This third type of epidemic may be associated with more complex emergency situations involving political instability and displaced populations (derived from WHO, 2002).

uations confronting control services.

Analysis of previous epidemics provides some understanding of their underlying causes and offers opportunities to develop indicators for predicting and monitoring the conditions that are likely to give rise to new epidemics. This should enable the development of an epidemic early warning system, which, when combined with a flexible control plan, can lead to epidemic prevention (Connor et al., 1999).

\section{Risk maps for epidemic prone regions}

Climate anomalies are of primary interest when creating risk maps for epidemic prone regions. In warm semi-arid areas, temperature is rarely a limiting factor for malaria transmission. Insufficient rainfall, surface water and humidity, however, prevent malaria transmission from occurring on a regular seasonal basis. In highland fringe areas rainfall and humidity may be sufficient for malaria transmission, but relatively cool conditions normally slow down the parasite's reproductive cycle to the extent that it is longer than the life span of its mosquito host. Consequently, transmission does not often occur in these regions (Fig. 2). Clearly, anomalies in these variables have important implications for allowing transmission among human populations with little or no immunity to the disease. Maps using deviations from mean climatology to demarcate epidemic prone regions suffer from the same issues as endemic risk maps discussed above, including changes in which zones are epidemic prone as a result of inter-decadal variability and longer term climate trends.

\section{Routine monitoring products for epidemic prone} regions

Experience to date has shown that it is difficult in terms of availability, timing and cost to obtain meteorological observations from national meteorological services in Africa. National health services generally find the costs of purchasing these data prohibitive given their competing demands for resources across the spectrum of health service requirements. A number of those that have paid for meteorological data, with the assistance of external project funding, have found its delivery to be too 


\section{Areas at risk of epidemic malaria}

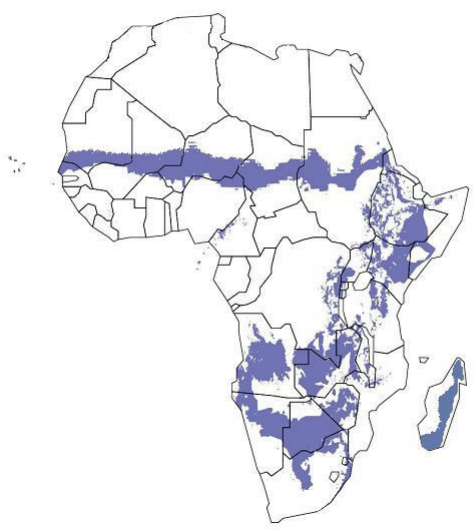

Fig. 2. Epidemic prone regions in Africa.

slow and irregular for use in an early warning application.

As with other sectors, health services have invested in their own hydro-meteorological network. The Onchercerciasis Control Programme, for example, established and maintained a comprehensive stream flow monitoring system across major river systems in West Africa as part of its vector control activities. Recent investments from the World Bank in malaria control have included the provision of meteorological stations at health facilities in Eritrea. In Niger, project funding has resulted in the creation of 44 meteorological stations directly maintained and run by health staff. Rainfall, temperature and humidity data are recorded directly as part of electronic disease surveillance. These data are sent by satellite to the central levels of the Ministry of Health, and its partners, on a weekly basis. The use of this high technology however raises issues of sustainability and quality control.

Others have tried to overcome this problem of access by using proxies derived from meteorological satellites, which tend to be available free of charge, in 'near-real-time' and therefore offer much promise for monitoring applications (Ceccato et al., 2005). The increasing capacity and affordability of personal computers means that these large and complicat- ed sets of data can be stored and analyzed with relative ease. Furthermore, innovative methods of data capture, such as remote sensing; and the visualization of data from multiple sources offered by spatial data handling software, such as geographic information systems, have greatly increased. These developments, combined with the possibilities for information sharing provided by the Internet, offer an unprecedented window of opportunity to increase their usefulness and applicability to developing country needs.

There are several satellite-derived rainfall estimates available. While some of these products are intended for research purposes, others are more appropriate for routine operational monitoring. Temperature monitoring products currently remain mostly in the research realm. Satellite-derived estimates of rainfall and temperature cannot completely overcome the need for ground-based observations, however, which are essential for testing and validating sensors and estimation methods. This brings us once again to the problem of access to sufficient data and interpolation methods used, in this case, in the satellite products. If the data available to national meteorological services were available to the developers of satellite estimation products, then these could be substantially improved. National meteorological services could better serve their national development partners, in health and other climate sensitive sectors, by making these data available to them as well.

Despite these problems, studies have shown that monitoring rainfall anomalies has the potential to provide advanced warning of impending epidemics in several areas, including Kenya, Ethiopia, Eritrea, West Africa and Botswana (Thomson et al., 2006). In Eritrea the use of remotely-sensed images for monitoring rainfall is now part of the routine monitoring system. The National Malaria Control Program based in Asmara uses the web-based Malaria Early Warning System (MEWS) interface developed by the International Research Institute for Climate and Society (IRI) staff. The MEWS enables users to gain a contextual perspective of the 
current rainfall season by comparing it to previous seasons and recent short-term averages. The rainfall estimates are updated every 10 days through the Africa Data Dissemination Service (ADDS), which is maintained by the United States Geological Survey (USGS) and supported by the U. S. Agency for International Development (USAID).

The interface is available through the IRI Data Library and takes the form of an online 'clickable map': http://iridl.ldeo.columbia.edu/maproom/.Health/.Re gional/.Africa/.Malaria/.MEWS/. It displays the most recent dekadal rainfall map over which national and district administrative boundaries and the epidemic risk zone can be overlaid. These visual features can be toggled on or off and the user can zoom in to any region for more clarity. In addition, the map can be downloaded in different formats compatible with common Image Analysis and Geographical Information Systems (GIS) software such as ArcView ${ }^{\circledR}$ or HealthMapper (free GIS software developed by UN World Health Organization).

Dekadal rainfall can be spatially averaged over a variety of user-selected areas, including administrative districts and $11 \times 11 \mathrm{~km}, 33 \times 33 \mathrm{~km}, 55 \times 55 \mathrm{~km}$ and $111 \times 111 \mathrm{~km}$ boxes. Upon the selection of this sampling area and a specific location of interest (by a click on map), four time-series graphs are generated. These time-series provide an analysis of recent rainfall with respect to that of recent seasons and the recent shortterm average (see Fig. 3 and Fig 4). A description of

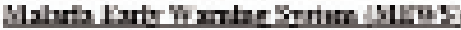

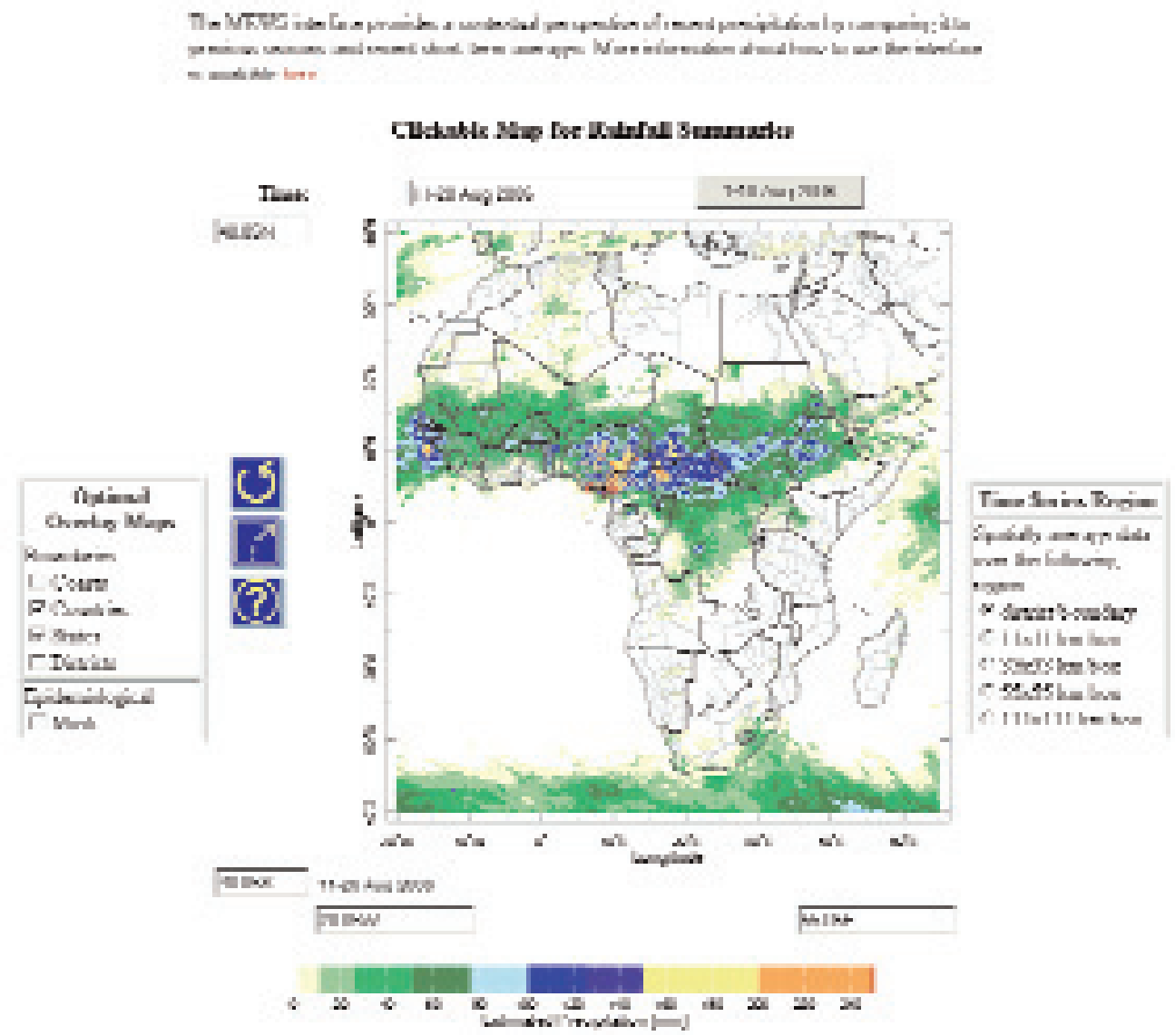

Fig. 3. Malaria Early Warning System 'Clickable Map' for rainfall monitoring. 

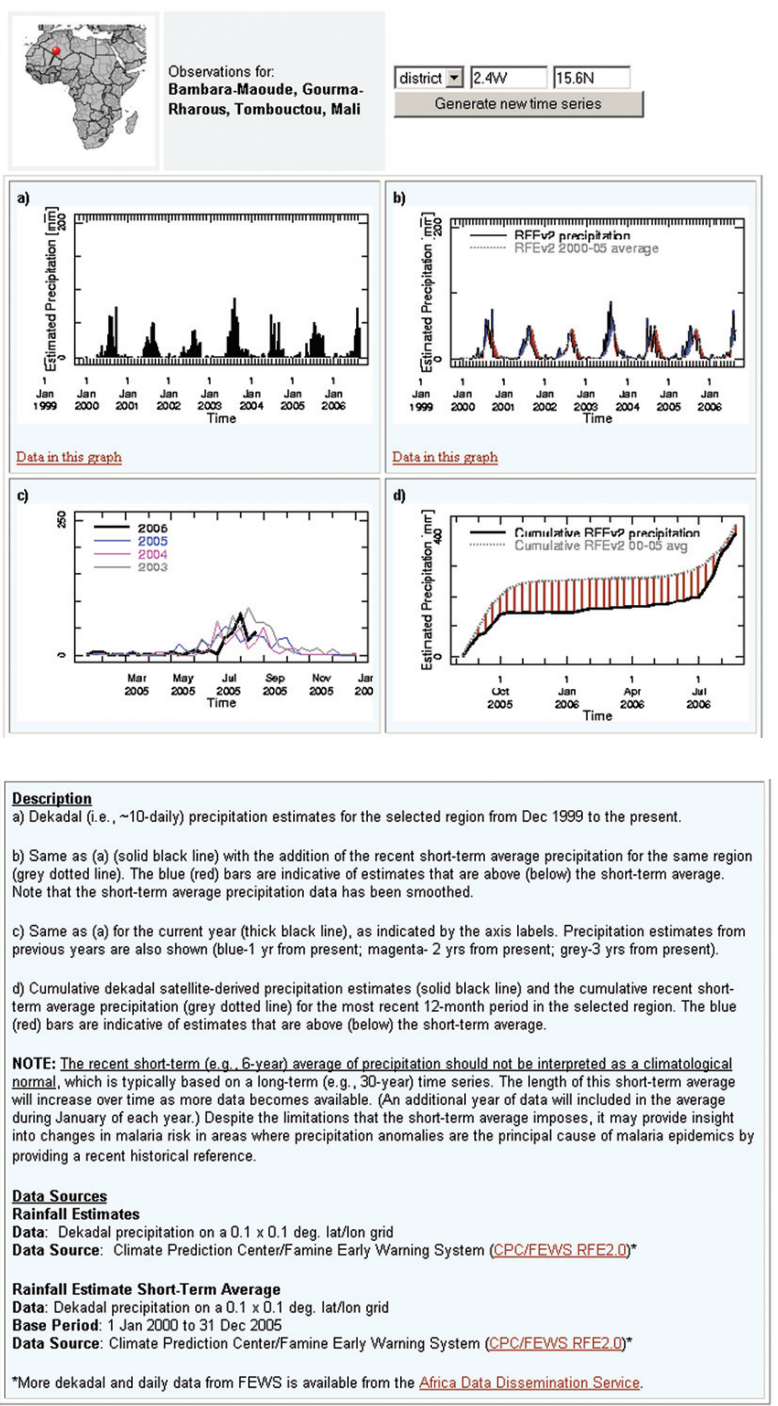

Fig. 4. Malaria Early Warning System 'Clickable Map' for rainfall monitoring with summary information on current rainfall/seasonal development for location of interest.

the time-series figures, the data used and its source is also provided (Grover-Kopec et al., 2005).

The type and growth stage of vegetation also play an important role in determining mosquito abundance irrespective of their association with rainfall. The type of vegetation which surrounds the breeding sites, and thereby provides, food, potential resting and protection from climatic conditions are also important in determining the abundance of mosqui- toes (Beck et al., 1994). Surface water provides the habitat for the juvenile stages (egg, larvae, pupae) of malaria vectors. Monitoring the state of vegetation and water bodies is therefore important to identify the source of malaria vectors. In order to monitor vegetation and water bodies, images from the satellite TERRA and sensor MODIS have been chosen because they provide frequent images at high spatial resolution $(250 \mathrm{~m})$ and are available free of charge (an important requirement considering the economic realities of the countries in the affected region). The products (vegetation indices 16-day L3 Global 250M SIN GRID V004) are automatically downloaded from the USGS Land Processes Distributed Active Archive Center (LPDAAC) and provided to the user community via the IRI Data Library web site: http://iridl.ldeo.columbia.edu/maproom/.Health/.Re gional/.Africa/.Malaria/ (see Fig. 5 and Fig. 6.)

The users can download either the raw data which are the single channels in the blue, red, near-infrared (NIR) and short-wave infrared (SWIR) wavelengths in different formats compatible with common Image Analysis and GIS software as well as the Normalized Difference Vegetation Index (NDVI) and Enhanced Vegetation Index (EVI) (Huete et al., 2002). Using the IRI Data Library, the users can remotely (via the Internet):

(i) combine the different channels to create their own tailored vegetation indices for monitoring; e.g. vegetation status in terms of moisture content by using a combination of the NIR-SWIR (Ceccato et al., 2002);

(ii) visualize a color composite of the SWIR-NIR and Red channels (Red-Green-Blue) where the vegetation appears in green, the bare soils in brown and the water in blue;

(iii) integrate the color composite into GIS software with ancillary data such as roads and villages;

(iv) extract weighted averages of the different indices per GIS layers such as district contours or any other shape file;

(v) create long-term time series of vegetation indices (Ceccato et al., 2006).

In Botswana, it was shown that further advanced 


\section{MCDis lnage Dewalead Teat: Hern of AMra}

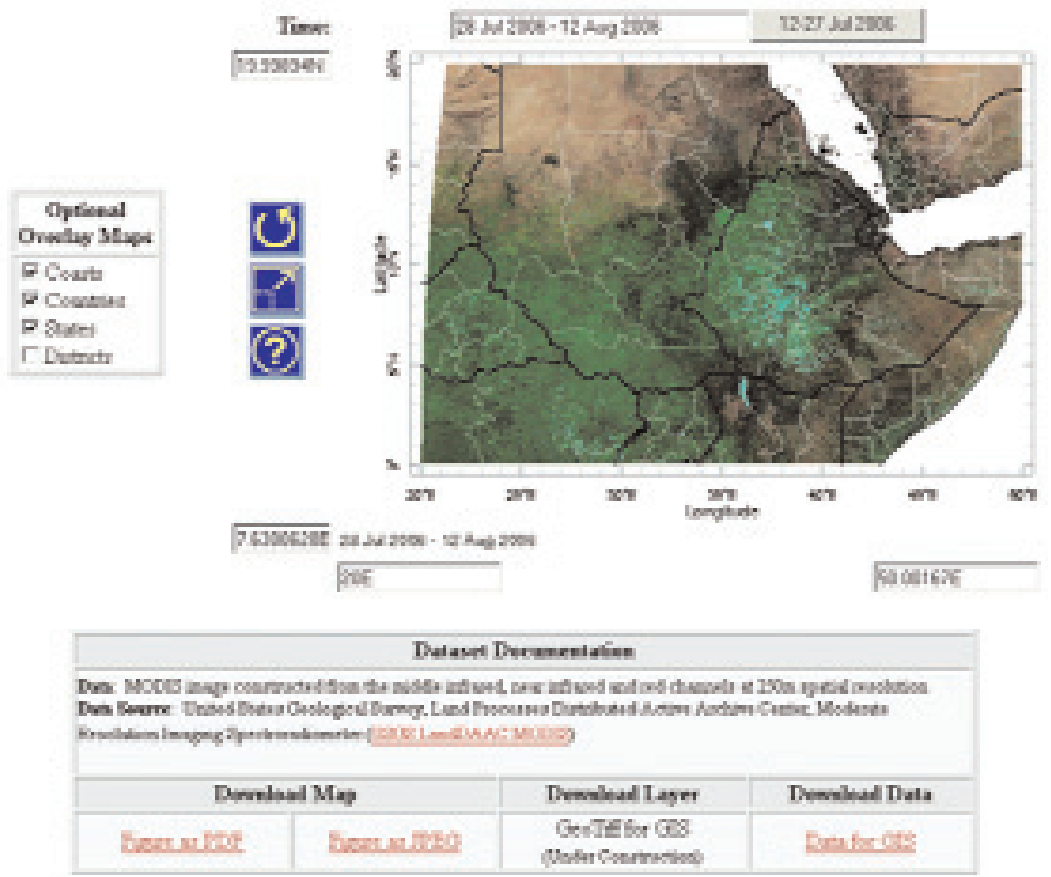

Fig. 5. MODIS Image Download Tool available through IRI Data Library.

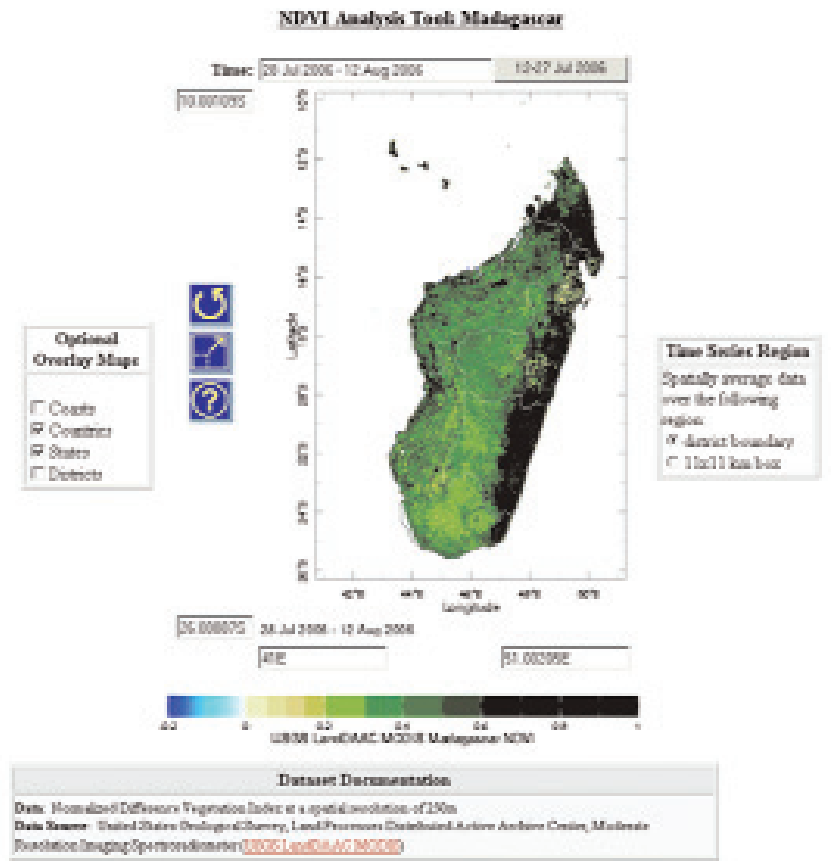

Fig. 6. MODIS Image NDVI Analysis Tool available through IRI Data Library. 
warning of epidemic risk could be achieved by including seasonal climate forecasts into the malaria early warning system framework (Thomson et al., 2005, 2006). The southern African region, which has a long history of malaria epidemics, now has the most advanced integrated approach to epidemic malaria control based on the evidence of the key determinants of epidemics in the region (Craig et al., 2004a,b; Thomson et al., 2005). These include climatic factors such as changes in rainfall and temperatures, as well as non-climatic factors such as changes in drug resistance, declining health infrastructure and migrations of non-immunes, or 'parasite carriers' into regions of differing risk. Experience and evidence for use of an integrated warning system approach within a national malaria control program has been demonstrated in Botswana over the past few years (Thomson et al., 2005). Other countries in the Southern African Development Community agree that this approach provides a useful framework for planning epidemic preparedness and response strategies. The WHO Southern Africa Inter-Country Programme for Malaria Control (SAMC) has supported them in exploring these tools further (Da Silva et al., 2004). As a result the region has now, for the second year running, prepared for the malaria season with a regional meeting (i.e. Malaria Outlook Forum) at which national and local vulnerability is assessed in the context of the pre-rainy season climate forecasts that have been tailored to the malaria community.

However, while such developments in computer and allied technologies are very welcome, their provision alone will do little to help solve the problems surrounding lack of capacity in sub-Saharan Africa. There is a massive need for institutional capacity strengthening, including the development and training of human resource capital. To get the relevant tools into practical use in routine decision-making a number of issues must be addressed.

These are:

(i) the problems identified and their potential solutions must stem from the needs and perspectives of the users and not the data/product sup- pliers and developers, thus ensuring that the demand is real;

(ii) costs of developing and maintaining the tools and training curricula will ideally be met with monies over which national agencies have full command, even if they originate from donor sources, thus ensuring that the choices made and priority rankings are their own;

(iii) training needs to be trans-disciplinary and delivered through carefully selected national and regional institutions that can grow and be capable of maintaining the demand for specialised personnel (who may well move out of the original sector to take other jobs in the labour market as their skills base increases);

(iv) interfacing climate and health is a new disciplinary area and requires long-term investment in boundary institutions and the development of a hierarchy of curricula and training materials for use at different levels of the health sector. This needs to be combined with a backdrop of problem-focused research activity which incorporates the latest health and climate knowledge;

(v) good career opportunities need to be apparent to attract those who are interested in working in this interface.

Given the current status of institutions in subSaharan Africa the above will undoubtedly need to be supported by development partners through the medium term. If national research and educational establishments are strengthened, then they will have a significant role to play. To ensure sustainability, national institutions that are accountable to their own constituencies and national development agendas must be leaders in this process.

\section{Opportunities - Integration of climate information into health information systems}

The current momentum and investment in strengthening health systems and reducing disease in sub-Saharan Africa is unprecedented. Investment in research and operational delivery of climate infor- 
mation products for climate sensitive-disease control would be highly valuable in helping to maximize the effectiveness of control program planning and implementation.

\section{Policy congruence}

There is currently a good deal of policy congruence through international, regional and local levels to support this effort. The remaining challenge is to get the knowledge into practice and sustaining it where it is needed. Allied initiatives stress that many of the time-bound goals and targets of the MDGs (health and non-direct health) are climate sensitive. In order to achieve the MDGs in health it is crucial that appropriate polices are developed and implemented to improve health system performance (Travis et al., 2004). This may be helped by enhancing the workforces' ability to detect and treat diseases, monitor and predict spatio-temporal patterns and implement intervention and control strategies in a timely and cost-effective manner through the use of tools and analysis informed by climate data.

The current policy context for the control of epidemic malaria

In order to get research outcomes into policy and practice it is important to understand the context in which different policies are adopted and supported in a practical manner. Below is an example of how policies developed at the district and national level connect to the larger political agenda of international policy makers.

\section{Global}

Improved early warning, prevention and control of epidemics is one of the key technical elements of the current Global Strategy for Malaria Control (WHO, 1993) and the Roll Back Malaria (RBM) Partnership (Global Strategic Partnership for RBM 2005-2015: http:/www.rollbackmalaria.org/forumV/ docs/gsp_en.pdf).

\section{Regional}

The African Heads of State declared their support for the Roll Back Malaria initiative in Africa in April 2000 with the Abuja Targets (WHO, 2000). In these targets national malaria control services are expected to detect 60 percent of malaria epidemics within two weeks of onset, and respond to 60 percent of epidemics within two weeks of their detection. With the support of the WHO Regional Office for Africa, the WHO InterCountry Programme Teams engage in the development of recommendations, guidelines and technical support to improve transboundary/cross border prevention and control of epidemics within their various sub-regions (e.g. Regional Economic Communities (RECS) ECOWAS, IGAD and SADC) including collaborative activities with the African Development Bank.

\section{National}

As a consequence of these policy developments, countries which are epidemic prone have: demarcated epidemic/endemic prone areas; established epidemic malaria surveillance systems in epidemic prone areas; strengthened their epidemic response capacity (with the assistance of the Global Fund for AIDS, Tuberculosis and Malaria (GFATM) and other donor support).

In many national malaria control policy documents, countries now recognize that to achieve the Abuja targets they need better information on where epidemics are most likely to occur, and, ideally, some indication of when they are likely to happen. As a consequence, they have begun to explore the use of climate information in the development of integrated early warning systems.

Thus there is increasing congruence in policy initiatives from multilateral, bilateral, national and non-governmental agencies in relation to epidemic disease control and a growing demand for climate 
information and the development of early warning systems to support these efforts.

\section{Linking health policies for climate-sensitive diseases to understanding climate change}

This policy congruence extends to the current discussions on adaptation to climate change. Strengthened health systems are also seen as vital to improving the management of climate-sensitive disease in the context of climate change. The International Panel on Climate Change (IPCC) identified building public health infrastructure as:

"The most important, cost effective and urgently needed adaptation strategy".

Other measures endorsed by the IPCC include public health training programs, more effective surveillance and emergency response systems, and sustainable prevention and control programs. These measures are familiar to the public health community and are needed regardless of climate change and constitute what is the basis of a "no regrets" adaptation strategy (Grambsch and Menne, 2003).

\section{References}

Beck LR, Rodriguez MH, Dister SW, Rodriguez AD, Rejmankva E, Ulloa A, Meza RA, Roberts DR, Paris JF, Spanner MA, Washino RK, Hacker C, Legters LJ, 1994. Remote sensing as a landscape epidemiological tool to identify villages at high risk for malaria transmission. Am J Trop Med Hyg 51, 271-280.

Brown V, Issak MA, Rossi M, Barboza P, Paugam A, 1998. Epidemic of malaria in north-eastern Kenya. Lancet 352, 1356-1357.

Ceccato P, Gobron N, Flasse S, Pinty B, Tarantola S, 2002. Designing a spectral index to estimate vegetation water content from remote sensing data (Part 1: theoretical approach). Remote Sens Env 82, 188-197.

Ceccato P, Connor SJ, Jeanne I, Thomson MC, 2005. Application of Geographical Information System and Remote Sensing Technologies for Assessing and
Monitoring Malaria Risk. Parassitologia 47, 81-96.

Ceccato P, Bell MA, Blumenthal MB, Connor SJ, Dinku T, Grover-Kopec EK, Ropelewski CF, Thomson MC, 2006. Use of remote sensing for monitoring climate variability for integrated early warning systems: applications for human diseases and desert locust management. Proceedings IGARSS-IEEE conference Denver, Colorado, 31 July - 4 August 2006.

Connor SJ, Thomson MC, Molyneux DH, 1999. Forecasting and prevention of epidemic malaria: new perspectives on an old problem. Parassitologia 41, 439-448.

Craig MH, Kleinschmidt I, Nawn JB, Le Sueur D, Sharp B, 2004a. Exploring 30 years of malaria case data in KwaZulu-Natal, South Africa: Part I. The impact of climatic factors. Trop Med Int Health 9, 1247-1257.

Craig MH, Kleinschmidt I, Le Sueur D, Sharp B, 2004b. Exploring 30 years of malaria case data in KwaZulu-Natal, South Africa: Part II. The impact of non-climatic factors. Trop Med Int Health 9, 1258-1266.

Craig MH, Snow RW, Le Sueur D, 1999. A climate-based distribution model of malaria transmission in Sub-Saharan Africa. Parasitol Today 15, 105-111.

Da Silva J, Garanganga B, Teveredzi V, Marx SM, Mason SJ, Connor SJ, 2004. Improving epidemic malaria planning, preparedness and response in Southern Africa. Malaria J 3, 37.

Grambsch A, Menne B, 2003. Adaptation and adaptive capacity in the public health context. In: Climate change and human health. World Health Organization, Geneva: 220-236.

Grover-Kopec EK, Kawano M, Klaver RW, Blumenthal MB, Ceccato P, Connor SJ, 2005. An online operational rainfall-monitoring resource for epidemic malaria early warning systems in Africa. Malaria J 4, 6.

Grover-Kopec EK, Blumenthal MB, Ceccato P, Dinku T, Omumbo J, Connor SJ, 2006. Web-based climate information resources for malaria control in Africa. Malaria J 5, 38.

Haines A, Patz JA, 2004. Health effects of climate change. J Am Med Assoc 291, 99-103.

Huete A, Didan K, Miura T, Rodriguez EP, Gao X, Ferreira LG, 2002. Overview of the radiometric and biophysical performance of the MODIS vegetation indices. Remote Sens Environ 83, 195-213.

Hutchinson MF, Nix HA, McMahon JP, 1995. A Topographic and Climate Data Base for Africa Version 1.1. 
In: Canberra ACT 0200 Australia. Centre for Resource and Environmental Studies Australian National University.

Hulme M, Jones P, Mitchell T, New M, 2004. A comprehensive set of high-resolution grids of monthly climate for Europe and the globe: the observed record (1901-2000) and 16 scenarios (2001-2100). In: Tyndall Centre Working Paper 55, Norwich.

Jones G, Steketee RW, Black RE, Bhutta ZA, Morris SS, 2003. Study at BC: How many child deaths can we prevent this year? Lancet 362, 65-71.

Kizewski A, Teklehaimanot A, 2004. A review of the clinical and epidemiological burdens of epidemic malaria. Am J Trop Med Hyg 71, 128-135.

MARA, 1998. Towards an Atlas of Malaria Risk in Africa. In: Durban: MARA/ARMA, 30.

Omran AR, 1971. The epidemiologic transition: a theory of the epidemiology of population change. Milbank Memorial Fund Quarterly 4, 509-538.

Pascual M, Ahumada JA, Chaves LF, Rodó X, Bouma M, 2006. Malaria resurgence in East African Highlands: temperature trends revisited. PNAS 103, 5829-5834.

Phillips D, Verhasselt Y, 1994. Health and Development. London: Routledge.

Sachs JD, 2004. Health in the developing world: achieving the Millennium Development Goals. Bull World Health Organ 82, 947.

Sachs, JD, McArthur JW, 2005. The Millennium Project: a plan for meeting the Millennium Development Goals. Lancet 365, 347.

Smith KR and Ezzati M, 2005. How environmental health risks change with development: the epidemiologic and environmental risk transitions revisited. Annual Rev Environ Res 30, 219-333.

Thomson MC, Erickson PJ, Ben Mohamed A, Connor SJ, 2004a. Land use change and infectious disease in West Africa. In: Ecosystems and land use change. Edited by De Fries R, Asner G, Houghton R. Washington, DC: American Geophysical Union.

Thomson MC, Connor SJ, Ward N, Molyneux D, 2004b. Impact of climate variability on infectious disease in West
Africa. Eco-Health 1, 138-150.

Thomson MC, Mason SJ, Phindela T, Connor SJ, 2005. Use of rainfall and sea surface temperature monitoring for malaria early warning in Botswana. Am J Trop Med Hyg 73(1), 214-221.

Thomson MC, Doblas-Reyes FJ, Mason SJ, Hagedorn R, Connor SJ, Phindela T, Morse AP, Palmer TN, 2006. Malaria early warnings based on seasonal climate forecasts from multi-model ensembles. Nature 439, 576-579.

Travis P, Bennett S, Haines A, Pang T, Bhutta Z, Hyder A, Pielemeier N, Mills A, Evans T, 2004. Overcoming healthsystems constraints to achieve the Millennium Development Goals. Lancet 364, 900-906.

WHO, 1993. A global strategy for malaria control. In: World Health Organization, Geneva, 30 p.

WHO, 2000. The Abuja Declaration on Roll Back Malaria by the African Heads of State and Government, April 25th, Abuja, Nigeria. In: World Health Organization, Geneva, 13 p. WHO, 2001. Macroeconomics and Health: Investing in Health for Economic Development. Report on the Commission for Macro-Economics and Health. In: World Health Organization, Geneva, 213 p.

WHO, 2002. Strategic framework to decrease the burden of TB/HIV. In: World Health Organization, Geneva, 49 p.

WHO-WMO-UNEP, 2003. Climate change and human health. World Health Organization, Geneva, 322 p.

WHO, 2004a. World report on knowledge for better health. In: World Health Organization, Geneva, 162 p.

WHO, 2004b. Malaria epidemics: forecasting, prevention, early warning and control - From policy to practice. In: World Health Organization, Geneva, 59 p.

WHO, 2005a. Malaria and HIV interactions and their implications for public health policy. In: World Health Organization, Geneva, 38 p.

WHO, 2005b. Using climate to predict infectious disease epidemics. In: World Health Organization, Geneva, 54 p.

Worrall E, Rietveld A, Delacollette C, 2004. The burden of malaria epidemics and cost-effectiveness of interventions in epidemic situations in Africa. Am J Trop Med Hyg 71, 136-140. 